\title{
METHODS OF EXAMINATION
}

\section{Röntgen Rays}

(I) Villasevãglios, G. (Naples).--Röntgen rays in the diagnosis of ocular disease. (I raggi Röntgen nella diagnosi delle malattie oculari.) Arch. di Ottal., 9, 10, 11, 1916.

(1) Villasevãglios occupies two whole numbers and part of a third of the journal with his article, or rather book, on Röntgen rays in the diagnosis of ocular maladies. The first part occupies some 45 pages and deals with the theory and technique of Röntgen ray work. This makes no pretence to be exhaustive but serves as a useful introduction to the surgeon who has had no practical knowledge of the subject. The second part, which, with a series of plates and a bibliography, occupies 100 pages, deals with the practical use of the rays in the diagnosis of ocular disease and is divided into five chapters. The first chapter treats of the intracranial processes and anomalies of the shape of the skull which may cause optic atrophy, with special reference to hypophyseal tumours and oxycephaly. This chapter contains a series of useful diagrams illustrating the alterations that take place in the shape and size of the sella Turcica and sphenoidal sinus in acromegaly. The second chapter describes the various lesions of the orbital wall and base of the skull that cause ocular change (optic atrophy, muscular paralysis, etc.). The third chapter takes up anomalies of form of the orbital walls due to destructive inflammatory process, to hyperostosis or tumour formation. The fourth chapter deals with the radiographic examination of the accessory sinuses. The author is of opinion that stereoscopic examination with the screen is the most serviceable method to employ in the examination of the sinuses. The final chapter deals with the localization of foreign bodies. In this chapter all the well known methods of localization receive mention. Villaseväglios himself considers that stereoscopic methods, as first employed by J. Mackenzie Davidson, yield the most satisfactory results.

The work concludes with an illustrated description of eight cases from the author's own observations typical of the different conditions he has described in the previous chapters.

Although the paper contains no novelty it should serve as a useful guide to the ophthalmic surgeon in estimating the value of radiography in ophthalmology.

E. E. H.

(2) Van der Hoeve (Groningen).- Röntgen ray examination in cases of tumours of the orbit. (Röntgenuntersuchung bei Tumoren der Orbita.) Zeitschr. f. Augenheilk., November, 1917. 
(2) Van der Hoeve thinks that the X-ray examination is apt to be neglected in cases of orbital tumour. This is a pity, for a good radiogram will often afford valuable information regarding the nature of the growth, and its relations to surrounding structures. The deepest shadows are thrown by the osteomata, and more especially when they are eburnized. The more recent work of Lagrange and Birsch-Hirschfeld teaches that the older opinion which recommended a conservative treatment of osteomata is dangerous, for the majority of them if left in situ lead to death, as, for example, frontal sinus osteomata. The value of a radiogram in these cases lies in the information it may give as to the point of origin of the bony growth, and the best way of attacking it. Most of the osteomata found in the orbit arise from one of the nasal sinuses. By operating upon the sinus it is generally much easier to remove the tumour than it would be by the orbital route. The Röntgen rays may prove useful in soft growths in the orbit. Van der Hoeve describes a case of this character. The tumour was removed by Rollet's method in preference to Krönlein's. Rollet points out that the contents of the orbit are not in direct contact with the periosteum, but are separated by an aponeurosis. There is a definite space between this aponeurosis and the periosteum which the anatomists have so far failed to describe. At Rollet's request Professor Laturget has investigated the space. Rollet finds that tumours often develop in it which may compress the muscle cone without implicating the structures which form it. The presence of tumours in this space, which contains no blood-vessels, favours an operation for extirpation.

The paper contains examples of Röntgen photographs, and of a section of one of the tumours removed.

T. HARRISON BUTLER.

\section{BOOK NOTICES}

The Medical Annual, I918. Liverpool : John Wright \& Sons, Ltd. Price 10/- net.

The space allotted to eye disease in this valuable summary of the year's work is again given to A. Hugh Thompson. The first three pages deal with general therapeutics, and give abstracts of recent papers on radium, thyroid, pilocarpine sweats, the treatment of hypopyon keratitis, subconjunctival injections, and the use of heat short of cauterization. A brief account of the recent literature on concussion injuries of the eye and visual part of the brain follows, in which mention of the work of Collins, Lister, Gordon Holmes, Riddoch and Kinnier Wilson (spelt Kinnear) is made. This is followed by an abstract of Whiting and Goulden's paper 